\title{
Land Use Classification Utilizing Thermal Band - Based on Wavelet Transform
}

\author{
Turkan A. Khaleel \\ Department of Computer Engineering \\ College of Engineering \\ Mosul University
}

(Received II/ $/ 2007$, Accepted 10/10/2007)

\begin{abstract}
Thermal band is generally not applied for land use classification, in the application of remote sensing, due to its inferior spatial resolution. However, thermal band data possess valuable informations, especially in the expression of the temperature of the Earth's surface and land cover and hence cannot be neglected.

The present study aims at the interpretation of data within the thermal band in the land use classification after merging with other bands and by using wavelet transform method.

The study focuses on two main parts; the first is the use of Mahalanobis Distance (Mah) method for land use classification. The method gave good results when applied to multi-spectral TM images of Mosul city, in comparison with other conventional methods. The second part is the adoption of a new method for merging thermal band TM6 with the remaining bands, on the basis of wavelet transform and the use of different wavelet filters such as Daubechies ('db4'), Symlet ('sym4'), and Coiflet ('coif4').

Finally, the method of merging thermal band with other band and using wavelete transform is compared with other conventional methods, like principle component analyses (PCA). It was noted that using wavelet transform, the classification accuracy is better. The best results are obtained in the third level, when using 'db4' wavelet filter. It has also been noted that urban areas are completely separated from the barren regions, in addition to the separation of different agricultural regions. This means that the thermal band informations are of great value in the classification of land use.
\end{abstract}

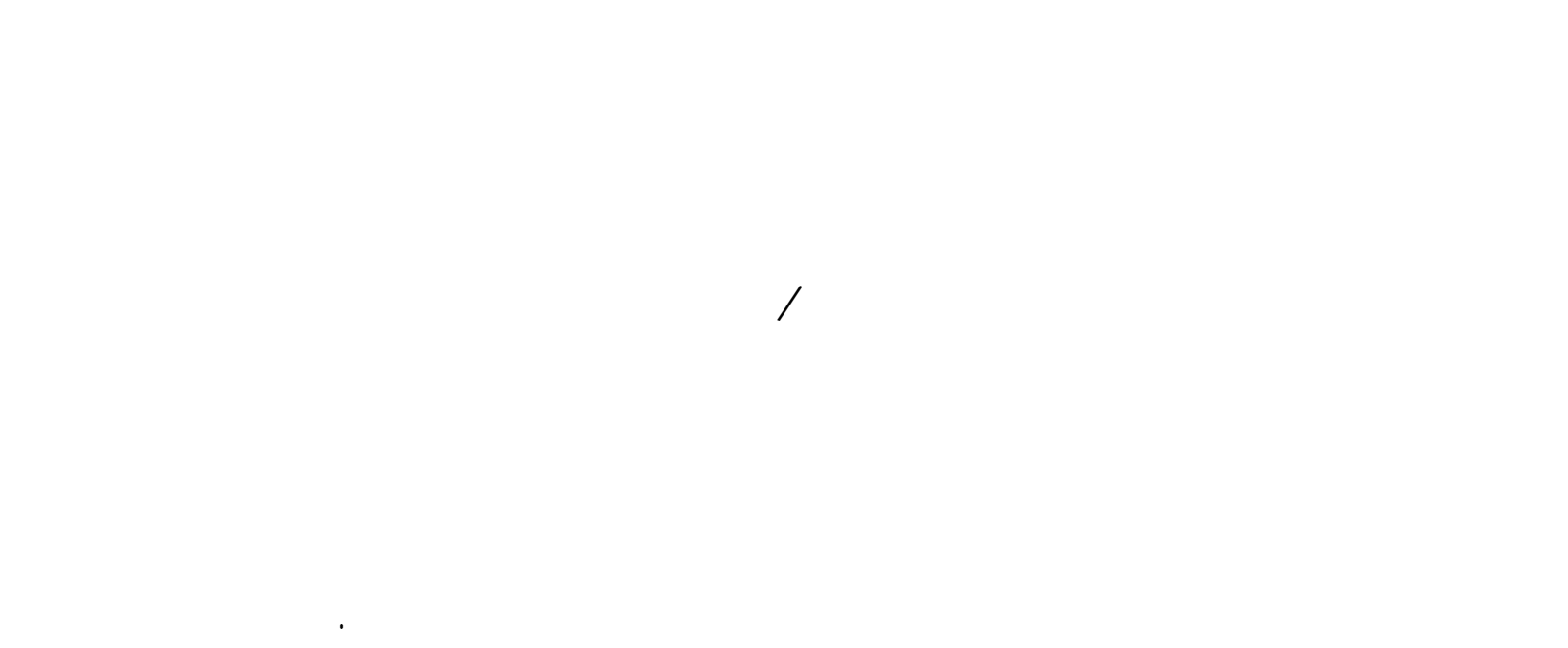


الحرارية تمتلك معلوملت مفية جداً وخاصة في التعبير عن درجة حرارة الأرض والطاء الأرض مي ولا يمكن إهمالها.

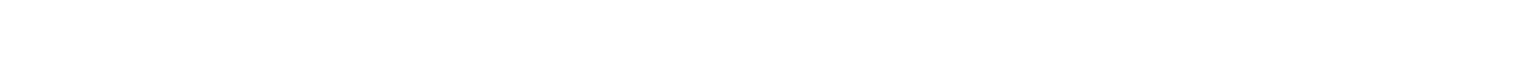
لستخدلم الأراضي بعد إملجهامع الحزم الطيفية الأخرى بلستخدلمطريقة التحويل المويجي.

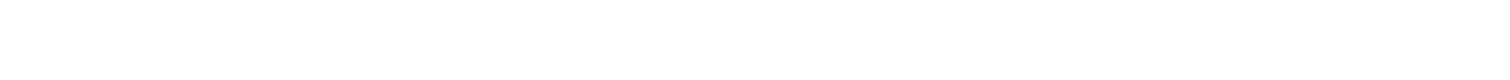
Mahalanobis Distance الأطيف لمتهس TM الملنظة لمدينة الموصل كانت النتائج جيدة مقارنة مع الطرق القليدية.

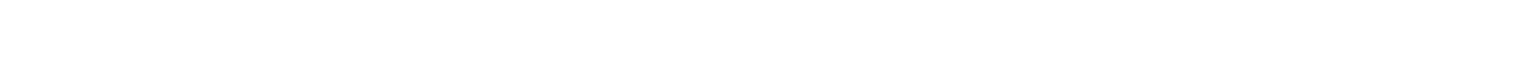
TM مختلفة مل: مُشعح ' 'db4' و 'sym4' و 'coif4'.

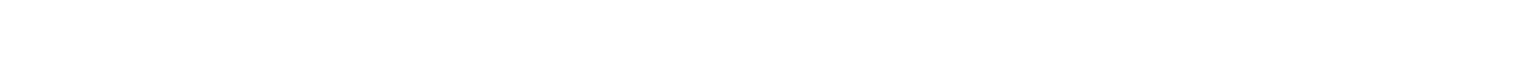

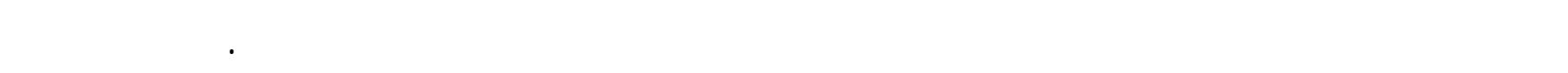

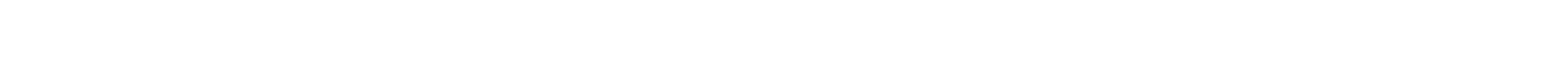

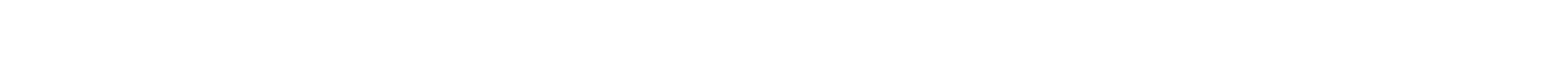

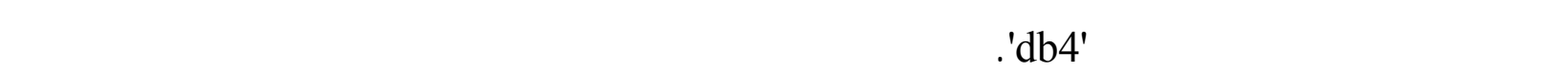

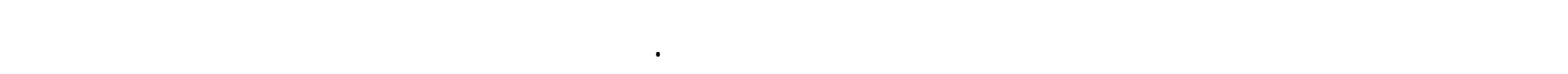
معلوملت مفيدة قفيد كثيرا في تصنيف لستخدلمات الأراضي.

\section{INTRODUCTION}

The term land use refers to how the land is being used by human beings. Land cover refers to the biophysical materials found on the land. For example, the state park may be used for recreation but have a coniferous forest cover (Jensen, 2007). USGS land use and land cover classification system for use with remotely sensed data and representation types of data typically used to provide the information. This system includes (I-IV) levels (Anderson et al., 2001).

In the application of remote sensing technology, especially when using multispectral bands in the land use and land cover classification thermal infrared band is often neglected. The reason for this is the different spatial feature and resolution. Many workers neglected thermal band for classification of multi-spectral imagery for the same reason such as (Zahn, 1995; Al-Shumam, 2001).

But thermal band data is potentially useful, highlighting reductions in temperature associated with recent irrigation, and earth's surface and land cover, with the possibility of its use for water control and the different stages of the crop growth (Lavers, et al., 2005). For this reason the aim of this research is to improve the accuracy of spatial resolution of thermal band TM6 from 120 meters to 30 meters and to use it with other remaining bands in the land use classification for the city of Mosul. 
These methods are known as image fusion techniques. Some of the popular techniques are the intensity, hue, and saturation (IHS), principl component analysis (PCA), and the Brovey transform (Pradhan and King, 2006). Several approaches to image fusion can be distinguished, depending on whether the images are used in the spatial domain or they are transformed into another domain, and their transforms are fused. In the field of the remote sensing, the wavelet transform is an effective technique for the fusion of different resolution images, because this technique is one of the least to cause the destruction of data features (Li et al., 1994).

In this study image fusion based on wavelet transform is used to include thermal band TM6 with the remaining six bands and the results are applied for land use classification for the city of Mosul.

There are several studies in this scope, like (Schistad Solberge et al., 1994), (Yu, et al., 2002) and (Lu and Weng, 2005). These workers proposed a model which uses images taken at different times for different sources, and applied for land use classification. While (Das et al., 2001) suggested spatial filtering mean and weighted average filter and data fusion to improve the effective spatial resolution of Landsat-5 TM band6. They used maximum likelihood classification for urban land use classification. On the other hand, (Qub'a, 2001) submitted a study image fusion scheme based on the wavelet transform. The scheme uses many fusion models such as the replacement model and the contrast-variance model. Sun et al., (2003) proposed an information fusion method for the extraction of land use information based on both the panchromatic and multi-spectral. It integrates spectrum of spatial and structural informations existing in the image. By this method a thematic map was first produced with the maximum likelihood classification applied to multi-spectral imagery, and probabilistic relaxation was then performed on the thematic map to refine the classification with neighborhood information.

The purpose of the present study differs from all previous works; it uses a complete program using wavelet transform to include thermal band6 with other TM bands. Then, this program uses Mahalanobis distance classifier to classify seven multispectral images of Mosul area to produce land use classification and good results are obtained in comparison with those using original band without band6.

\section{MAHALANOBIS DISTANCE CLASSIFIER}

In this study, Mahalanobis distance has been used because it takes the variability of classes into account, unlike Minimum Distance (MD) or Parallelpiped classifier. It may be more useful than minimum distance in cases where statistical criteria (as expressed in the covariance matrix) must be taken into account, but the weighting factors that are available with maximum likelihood/ Bayesian(ML) option are not needed (Tso and Mather, 2001).

The equation for the Mahalanobis distance classifier is as follows:

$$
D^{2}=\left(X-\mu_{c}\right)^{T} \operatorname{Cov}_{c}^{-1}\left(X-\mu_{c}\right)
$$

where :

$D^{2}$ : Mahalanobis distance.

$C$ : particular class.

$X$ : the measurement vector of the candidate pixel. 
$\mu_{c}$ : the mean vector of the signature of class $c$.

$\operatorname{Cov}_{\mathrm{c}}$ : the covariance matrix of the pixels in the signature of class $c$.

$\operatorname{Cov}_{c}^{-1}$ : inverse of $\operatorname{Cov}_{c}$.

$T \quad$ : transposition function.

The pixel is assigned to the class $c$, for which $D$ is the lowest.

\section{DISCRETE WAVELETE TRANSFORM (DWT)}

The basic operation for calculating the DWT is convolving the samples of the input with the low-pass and high-pass filters of the wavelet and down sampling the output (pradhan et al., 2006). This transform is performed by the following two equations (Qub'a, 2001):

$$
\begin{aligned}
C_{j, k} & =\sum_{n=-\infty}^{\infty} X(n) \varphi_{j, k}(n) \\
d_{j, k} & =\sum_{n=-\infty}^{\infty} X(n) \psi_{j, k}(n)
\end{aligned}
$$

where :

$C_{j, k} \quad:$ Approximation coefficients

$\varphi_{j, k}(n):$ scale function

$d_{j, k}(n):$ Detail coefficients

$\psi_{j, k}(n):$ Wavelet function

$X \quad$ : Input

Wavelet function is deduced from the following equation (Qub'a, 2001):

$$
\psi_{j, k}(n)=\sqrt{2^{j}} \psi\left(2^{j} n-k\right)
$$

Similarly, the scale function is deduced from

$$
\varphi_{j, k}(n)=\sqrt{2^{j}} \varphi\left(2^{j} n-k\right)
$$

It is possible to retrieve the reference of these transactions through (Qub'a, 2001)

$$
X(n)=\sum_{k=-\infty}^{\infty} C_{j o, k} \varphi_{j o, k}(n)+\sum_{j=j o}^{\infty} \sum_{k=-\infty}^{\infty} d_{j, k} \psi_{j, k}(n)
$$

Since image is 2D signal, it would mainly be focused on the 2D wavelet transforms. The following Figure (1) shows the structures of 2D DWT with 2 decomposition levels:

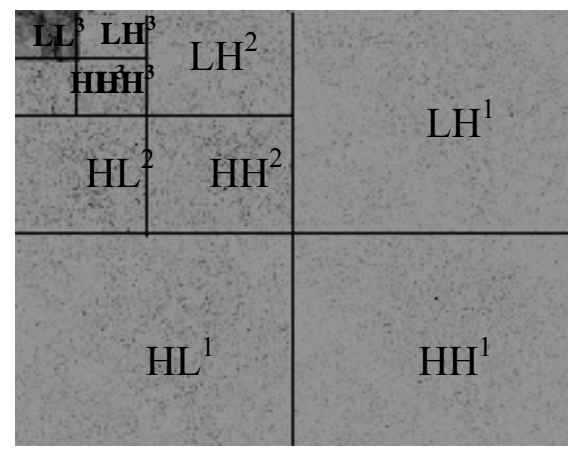

Fig.1: The structures of 2D DWT of third level 
Where

$\mathrm{H}$ : High frequency bands.

L: Low frequency bands.

$1,2,3, \ldots$ Decomposition levels.

After one level of decomposition, there will be four frequency bands, namely Low-Low (LL), Low-High (LH), High-Low (HL) and High-High (HH). The next level decomposition is only applied to the LL band of current decompodition stage, which forms a recursive decomposition procedure.

\section{IMAGE FUSION USING WAVELET TRANSFORM}

Fusion is an important technique with disparate fields such as remote sensing and computer vision. The fusion of images is the process of combining two images into a single image retaining important features from each of the original image.

Fusion techniques include the simplest method of pixel averaging to the more complicated method such as principal analysis and wavelet transform (Hill et al., 2002).

Wavelet transform fusion is more formally defined by considering the wavelet transform $W$ of the two registered input images image1 $(x, y)$ and image $2(x, y)$ together with the fusion rule $\phi$. Then, the inverse wavelet transform $W^{-1}$ is computed, and fused image fimage $(x, y)$ is reconstructed.

$$
\text { fimage }(x, y)=w^{-1}(\phi(w(\operatorname{image} 1(x, y), w(\operatorname{image} 2(x, y))))
$$

The following Figure (2) shows the Image fusion using wavelet transform.

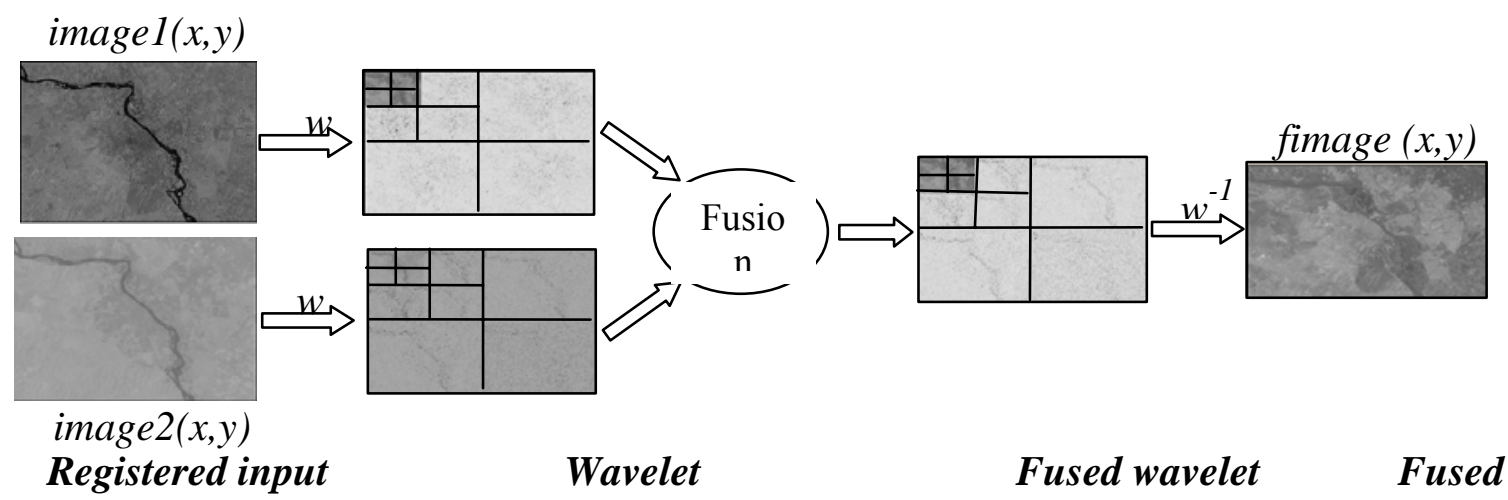

Fio 2: Image fusion usino wavelet transform

\section{RESULTS AND DISCUSSION}

In this study, a complete project program was designed to merge Landsat TM thermal band6 with remaining six TM bands and land use classification. This project was programmed using Matlab 7.0 and Microsoft Visual C++ Ver.6.0. This program comprises many choices to be benefited from in multi-spectral image classification, Plate(1) shows some of the windows of the program prepared in this research. One of these choices is False Color Composite image which is used in the test of training area to be used later in supervised classification. 
The image used in this study was extracted from a Landsat-5 Thematic Mapper scene taken over Mosul city, north of Iraq. Land sat TM records data in seven different bandwidths. These bandwidths are broken down into portions of visible, infrared, and thermal infrared regions of the electromagnetic spectrum. Ground resolution for the bands $1,2,3,4,5$, and 7 is 30 meters while for band 6 resolution is 120 meters.

The size of the images to be used is $866 \times 660$ pixels, Plate(2) shows false color composite image made of three bands 7,4 and 2 displayed in RGB respectively. In this composition, vegetation appears in bright green while some of agricultural fields appear in dark green and Tigris River can be identified in dark blue. Pixels are selected to represent patterns or land cover features that could be recognized, or could be identified with the help of other sources, such as ground information. Knowledge of the data and of the classes desired is required before land use classification. Table (1) shows classes and land use category.

Table 1: Land Use Category

\begin{tabular}{||c||r||}
\hline \multicolumn{1}{|c||}{ Class\# } & \multicolumn{1}{c|}{ Land use Category } \\
\hline \hline 1 & Water (Tigris River) \\
\hline 2 & Mixed Forest Land \\
\hline 3 & Urban or Built - up Land \\
\hline 4 & Wet land \\
\hline 5 & Rangeland \\
\hline 6 & Bgricultural land \\
\hline 7 & Mixed Rangeland \\
\hline 8 & \\
\hline
\end{tabular}

The next stage is to choose the suitable classifier to produce the land use classification. There are many conventional supervised classifications used in remote sensing to produce land use classification like, Minimum distances (MD), Maximum likelihood (ML), and Mahalanobis distance (Mah). This stage is useful for selecting the best classified images to give land use classification. When the accuracy of classification of each class and overall accuracy were measured, it was observed that MD recorded the least accuracy of $(90.843 \%)$, While ML and Mah recorded higher accuracy of classification of (95.402\% and 95.583\%) respectively, (Table 2). The reason for that was their capability of separating urban areas from wet land areas in addition to the other classes.

This is a good indicator which confirms that the last method (Mah) will qive better results if used for production of land use. In addition, it is a new algorithm for classification of remote sensing images.

After the completion of the selection of the best classifier, a new important step is applied, and includes the method of merging the thermal band6 with the reaming TM bands. In this study the fusion of thermal band with other TM bands is carried out by the following steps:-

1- Register all images geographically by the use of control points.

2- Load two original images, a mask(TM band) and a bust (thermal band6). 
3- Merge the two images from wavelet decompositions at 'level3' using wavelet filter ('cofi4', or 'sym4' or 'db4') by taking the 'minimum' for the approximations and the 'mean' for the details.

4- Save each output as a new image.

Table 2: The accuracy of indicial land use classes, and the overall accuracy using MD, ML and Mah

\begin{tabular}{|c|c|l|l|}
\hline \multirow{2}{*}{ Class\# } & \multicolumn{3}{|c|}{ Land use Category } \\
\cline { 2 - 4 } & MD & \multicolumn{1}{|c|}{ ML } & Mah \\
\hline 1 & 97.384 & 98.591 & 100 \\
\hline 2 & 97.802 & 85.714 & 95.604 \\
\hline 3 & 93.229 & 100 & 99.479 \\
\hline 4 & 86.026 & 96.069 & 100 \\
\hline 5 & 75.098 & 89.229 & 91.560 \\
\hline 6 & 98.113 & 98.427 & 98.742 \\
\hline 7 & 93.822 & 95.752 & 92.277 \\
\hline 8 & 85.269 & 99.433 & 87.006 \\
\hline $\begin{array}{l}\text { Overall } \\
\text { accuracy(\%) }\end{array}$ & 90.843 & 95.402 & 95.583 \\
\hline \hline \multicolumn{4}{|l}{} \\
\hline
\end{tabular}

After improving spatial resolution of the thermal band from $120 \mathrm{~m}$ to $30 \mathrm{~m}$ by using image fusion based on wavelet transform, the resulting images are used in the classification of land use. Plate (3) shows the land use classification results.

Classification results after integrating thermal band give better overall accuracy than multi-spectral bands without thermal band $(95.583 \%)$. Also the urban or built up areas completely separated from the rest of the other regions. This is an indication that thermal band data possess an important information, especially in land use and urban planning.

The image fusion using wavelet transform results are higher than the results of conventional methods such as PCA $(96.276 \%)$. On the hand, the results of classification of overall accuracy based on wavelet transform using different filters such as; 'coif4', 'sym4' and 'db4' are very close $(98.231 \%, 98.573 \%$ and 98.729\%), (Table 3$)$. It could be seen that best results are obtained when $\mathrm{db} 4$ ' at level3 is used. 
Table : The accuracy of indicial land use classes, overall accuracy of original TM bands without band 6 and including band 6 with remaining bands by using different fusion filters

\begin{tabular}{|c|c|c|c|c|c|}
\hline \multirow[t]{2}{*}{ Class\# } & \multirow{2}{*}{$\begin{array}{r}\text { Original } \\
\text { bands }(1-5,7) \\
\text { classification } \\
\text { without } \\
\text { band } 6\end{array}$} & \multirow{2}{*}{$\begin{array}{c}\text { Fusion TM } \\
\text { band } 6 \text { with } \\
\text { other TM } \\
\text { bands using } \\
\text { PCA }\end{array}$} & \multicolumn{3}{|c|}{$\begin{array}{l}\text { Fusion TM band } 6 \text { with } \\
\text { other TM bands using } \\
\text { different wavelet filters }\end{array}$} \\
\hline & & & 'cofi4' & 'sym4' & 'db4' \\
\hline 1 & 100 & 99.226 & 100 & 100 & 100 \\
\hline 2 & 95.604 & 95.604 & 98.901 & 95.604 & 95.604 \\
\hline 3 & 99.479 & 99.479 & 100 & 100 & 100 \\
\hline 4 & 100 & 100 & 100 & 100 & 100 \\
\hline 5 & 91.560 & 93.094 & 95.907 & 96.640 & 95.849 \\
\hline 6 & 98.742 & 97.169 & 100 & 100 & 100 \\
\hline 7 & 92.277 & 87.258 & 91.505 & 96.911 & 99.227 \\
\hline 8 & 87.006 & 98.375 & 99.535 & 99.433 & 99.150 \\
\hline $\begin{array}{r}\text { Overall } \\
\text { accuracy(\%) }\end{array}$ & 95.583 & 96.276 & 98.231 & 98.573 & 98.729 \\
\hline
\end{tabular}

\section{CONCLUSIONS}

From the analysis of the results of this study the following conclusions are drawn:

1 -Thermal band data is potentially useful, highlighting reductions in temperature associated with recent irrigation, and between the different stages of growth of the crops. In this research, land use classification utilizes Landsat TM thermal band gives better results than multi-spectral bands without thermal band. It is possible to use the thermal band in urban planning. Also urban areas are separated in an integrated way and it is possible to obtain more details if multi resolution sources from different sensor are used.

2-Combining Landsat TM thermal band6 with the remaining other bands based on the wavelet transform shows that more efficient results than other conventional method such as principal component analysis (PCA) are obtained best results are obtained when fusing the images from wavelet decomposition at 'level 3', using 'db4' by taking fusion method; 'minimum' for the approximation (TM bands) and 'mean' for the details (thermal band). Wavelet transform is useful if used in remote sensing applications because it is an effective technique for the fusion of different resolution images, it is one of the least to cause the destruction of data features.

3-Using Mahalanobis distance (Mah) method good results are obtained in comparison with other conventional methods such as MD and ML, because Mah takes the variability of classes into account, unlike MD and unlike ML does not need the weighting factors; this is a good indicator for use in the classification of multi-spectral images in remote sensing. 


\section{REFERENCES}

Al-Shumam T.A.K., 2001. An Integrated Software for Remotely Sensed Data Classification, Unpublished M. Sc. Thesis, University of Mosul, pp. 1-78.

Anderson J.R, Hardy E.E., Roach, J. T., and Witmer, R.E., 2001. A Land Use and Land Cover Classification System for Use with Remote Sensor Data Geological Survey Professional Paper 964. USA.

Das K. D., Rao G. K., and Prakah A., 2001. Improvement of Effective Spatial Resolution of Thermal Infrared Data for urban Land use classification, IEEE/ ISPRS Joint Work Shop on Remote Sensing and Data Fusion Over Urban Areas., pp. 332-336.

Hegde S., 2003. Modeling Land cover Change: A Fuzzy Approach, M.Sc. Thesis, Geo-information Science and Earth Observation, Indian Institute of Remote Sensing, TIC, $51 \mathrm{P}$.

Hill P., Canagurajah N., and Bull D., 2002. Image Fusion Using Complex Wavelets, Complex Proc., $13^{\text {th }}$ British Machine Vision Conf., University of Cardiff, U.K. pp. 487-496.

Jensen J.R., 2007. Remote Sensing of the Environment an Earth Resource Perspective, Second Edition, person prentice Hall, Pearson Education. Inc. Upper Saddle River, NJ07458, pp. 450-451.

Lavers C., Frank K., Floyd M., and Plowman A., 2005. Application of remote thermal imaging and night vision technology to improve endangered wildlife resource management with minimal animal distress and hazard to humans , Journal of Physics, Vol. 15, pp. 207-212.

Li H., Manjunath B. S. and Mitra K. , 1994. Multi-Sensor Image Fusion Using The Wavelet Transform, Proc. First International Conference On Image Processing, ICIP 94, Austin, Texas, Vol. 1, pp. 51-55.

Lu D. and Weng Q.,2005. Urban Classification Using Full Spectral Information of Landsat ETM_ Imagery in Marion County, Indiana, Photogrammetric Engineering \& Remote Sensing Vol. 71, No. 11, pp. 1275-1284.

Pradhan P.S., King R.L., 2006. Estimation of the Number of Decomposition Levels for a Wavelet-Based Multi-resolution Multi-sensor Image Fusion, IEEE Transaction of Geosciences and Remote Sensing, Vol. 44, No. 12, pp. 3674-3686.

Qub'a A.R., 2001. Multi Spectral Image Fusion Using Wavelet Transform, Unpublished M.Sc. Thesis, University of Msoul, pp.1-85.

Schistad Solberge A. H., Jain A. K., and Taxt T. 1994, Multi source Classification of Remotely Sensed Data: Fusion of Land Sat and SAR Image, IEEE Transactions on Geosciences and Remote Sensing, Vol. 32, No. 4, pp. 768778.

Sun W., Heidt V., Gong P. and Xu G., 2003. Information Fusion for Rural LandUse classification with High-Resolution Satellite Imagery, IEEE Transactions on Geosciences and Remote Sensing, Vol. 41, No. 4, pp. 883-890.

Tso B. and Mather P.M., 2001 Classification Methods for Remote Sensed Data, Taylor and Francis Inc. 
Weng Q., Liu H., and Lu D., 2007. Assessing the Effect of Land Use and Land Cover Patterns on Thermal Conditions Using Landscape metrics in City of Indianapolis, United States, Springer, Urban Ecosyst, Vol. 10, pp. 203-219.

Yu Z., Jixian Z., Guangliang W., and Zongjian L., 2002. Urban Land-Use Classification Using Integrated Airborne Laser Scanning Data and High Resolution Multi-Spectral Satellite Imagery, Pecora 15/Land Satellite Information IV/ISPRS Commission I/FIEOS 2002 Conference Proceedings, Chinese Academy of Surveying and Mapping, No.16, pp.1-6.

Zahn M., 1995. A Method to Classify MultiSpectral Images, Proc. of the International Geoscience and Remote Sensing Symposium IGARSS'95, IEEE Publications, Piscataway, New Jersey, Vol. 2, pp. 1162 - 1164

Plate1: Some of the most important program windows

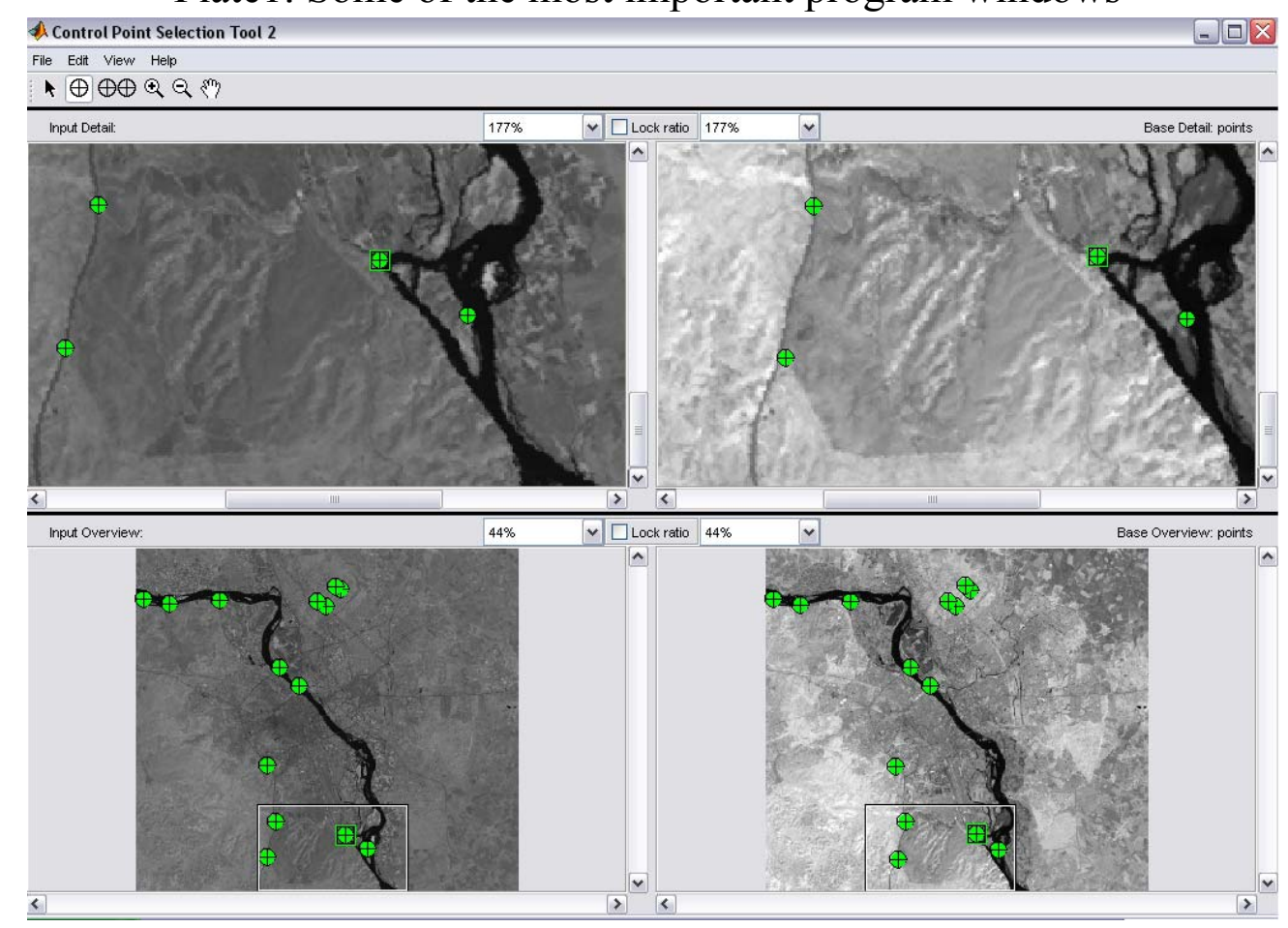

a- Register program window

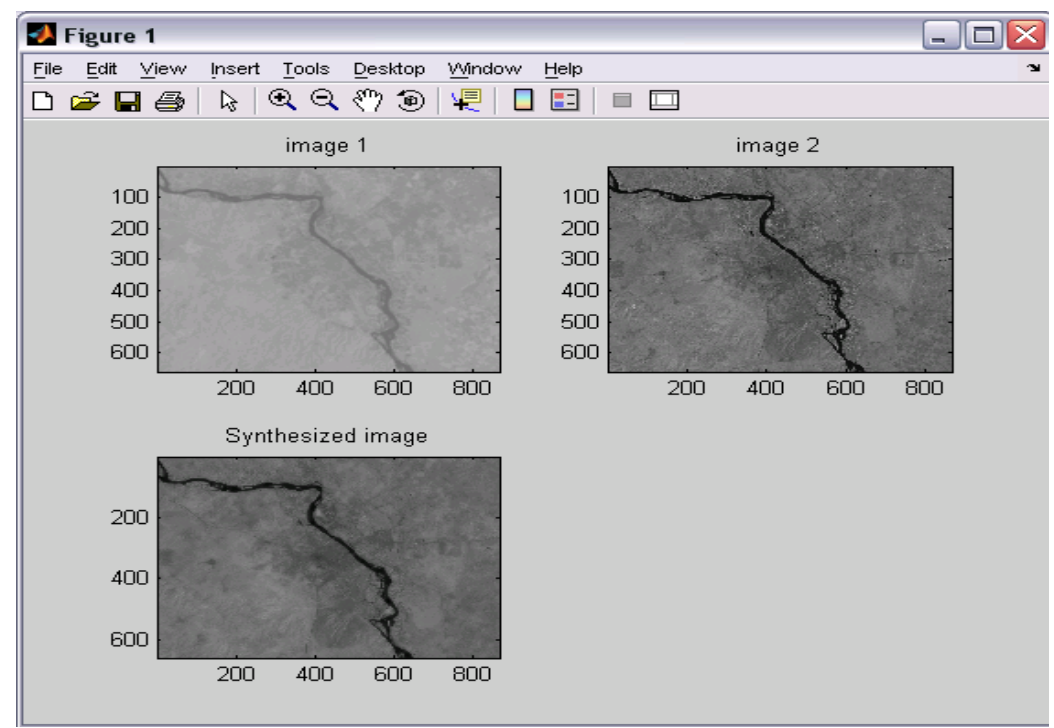

b- Images fusion using 2D-DWT program window 


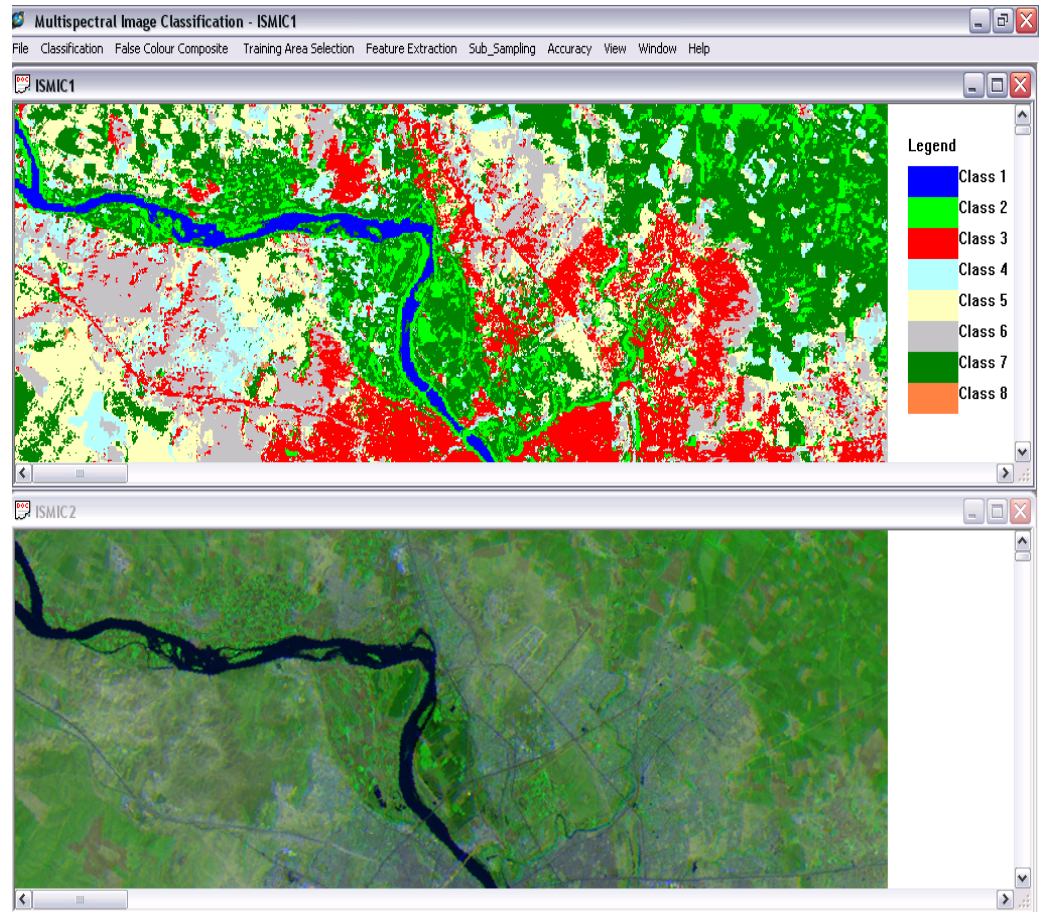

d- Multi-spectral image classification program windows

Plate 2: FCC's of Original Bands $(\mathrm{RGB}=7,4,2)$

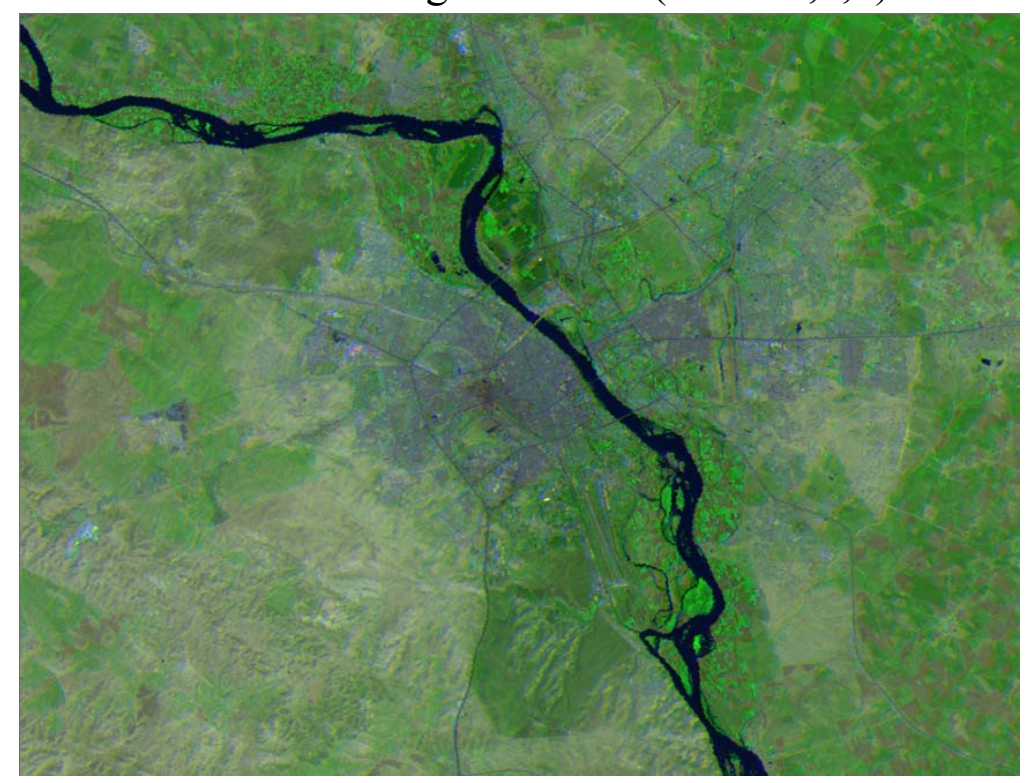


Plate 3: Land use Classification Results using Mahalanobis distance

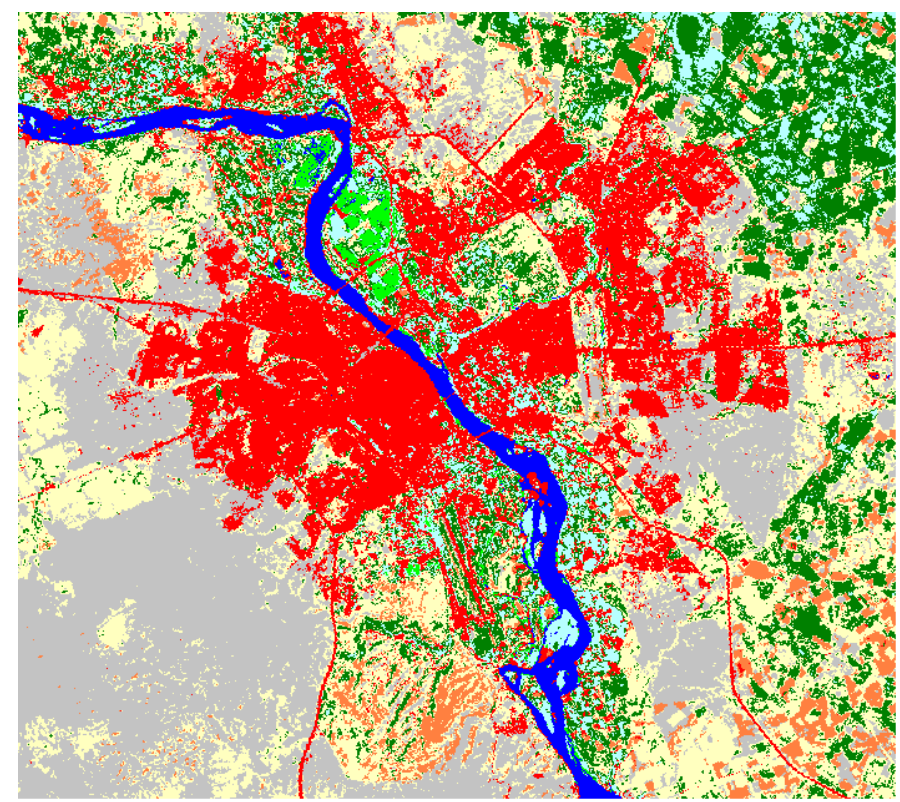

\author{
Land use Category

\begin{tabular}{l}
\hline Water (Tigris River) \\
Mixed Forest Land \\
\hline Urban or Built-up Land \\
Wet Land \\
Rangeland \\
Bad Land \\
Agricultural Land \\
Mixed Rangeland \\
\\
a- Multi-spectral \\
bands without \\
band6
\end{tabular}

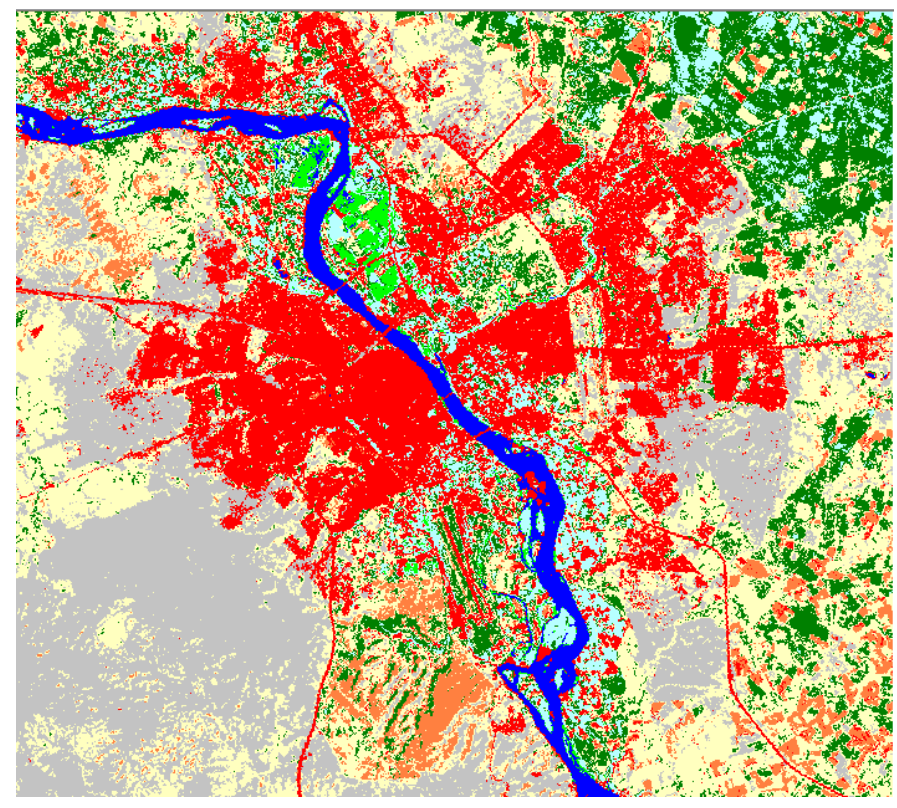

b- Multi-spectral bands

fusion band6 using PCA.

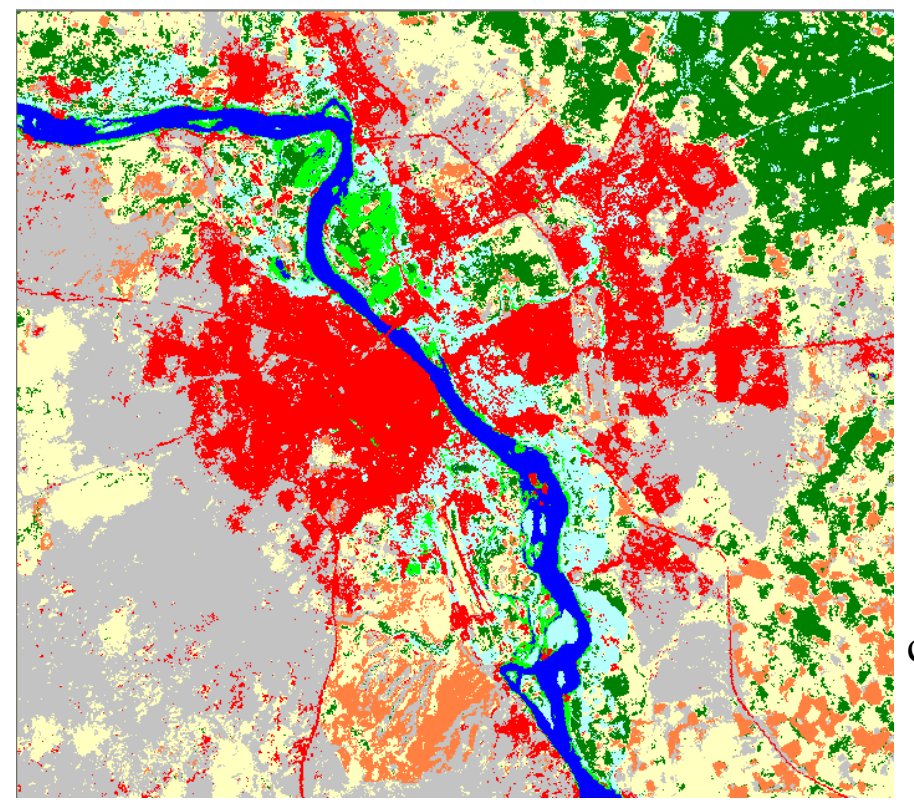

c- Multi-spectral bands fusion band6 using wavelet transform 'db4' filter 